\title{
Ultrastructure of conidia and hyphae of Stachybotrys chartarum
}

\author{
MARJO NIKULIN, KARI REIJULA, TUULA STJERNVALL AND EEVA-LIISA HINTIKKA
}

\begin{abstract}
NIKULIN, M., REIJULA, K., STJERNVALL, T. \& HINTIKKA, E.-L. 1997: Ultrastructure of conidia and hyphae of Stachybotrys chartarum. - Karstenia 37:5764. Helsinki. ISSN 0453-3402

The fine structure of two Stachybotrys chartarum strains, one toxic (S. 72) and one non-toxic (S. 29) was investigated by transmission electron microscopy (TEM). It is not known if certain morphological details of the fungus are correlated with its toxinproducing capacity. The hyphae and conidia in both strains possessed three wall layers: an electron lucent inner layer, more dense middle layer, and an electron dense outer layer. The outer layer in both strains was uneven and formed an echinulate surface on the conidium. Only minor morphological differences were observed between the toxic and non-toxic strains. The echinulate surface of the conidium of the non-toxic strain was thinner than that in the toxic strain and the outer surface of the hyphae of the non-toxic strain was smoother than the hyphal surface of the toxic strain.
\end{abstract}

Key words: electron microscopy, mycotoxins, Stachybotrys chartarum

Marjo Nikulin and Eeva-Liisa Hintikka, Faculty of Veterinary Medicine, Veterinary Microbiology and Epidemiology, University of Helsinki, and National Veterinary and Food Research Institute, P.O. Box 368, FIN-00231 Helsinki, Finland

Kari Reijula and Tuula Stjernvall, Indoor Air \& Environment Program, Finnish Institute of Occupational Health, Arinatie 3A, FIN-00370 Helsinki, Finland

\section{Introduction}

Stachybotrys chartarum (Ehrenb.) S. Hughes (syn. S. atra Corda; Deuteromycetes, Moniliales, Dematiaceae), is a saphrophytic fungus on cellulose-rich dead plant material, typically occuring as a black layer on nodes of cereals and grasses (Marasas \& Nelson 1987). It is cellulose-decomposing and has also been isolated from paper material (Hintikka 1977). Colonies on malt extract agar become black or blackish-green and powdery due to the conidial masses.

Feed contaminated with Stachybotrys chartarum is known to cause stachybotryotoxicosis in animals (Jong \& Davis 1976). Toxigenic isolates of $S$. chartarum produce several highly toxic macrocyclic trichothecenes and other compounds (Jarvis 1991, Jarvis et al. 1995). Stachy- botryotoxicosis may also occur in farm workers exposed to the fungus. The toxins can be absorbed through the skin and enter the lungs by inhalation, and illness may follow exposure to hay or straw contaminated by the fungus (Hintikka 1978). During recent years, Stachybotrys has often been isolated in air samples or samples taken from surfaces of building materials in houses with moisture problems (Bisset 1987, Croft et al. 1986, Hunter et al. 1988, Johanning et al. 1993, Miller et al. 1988). Conidia of $S$. chartarum contain mycotoxins (Sorenson et al. 1987). Cough, irritation of eye, skin and mucous membranes, respiratory symptoms, headache and fatigue observed in residents may be caused by inhaled toxins produced by the fungus. $S$. chartarum grows and produces toxins on moistened cellulose-containing respirator filters, 
wallpaper and gypsum board covered with cardboard (Nikulin et al. 1994, Pasanen et al. 1994).

Scanning electron microscopy (SEM) has been used in morphological studies of fungi (Samson et al. 1979), and also in identification and counting of fungal spores (Heikkilä et al. 1988). Transmisson electron microscopy (TEM) has been used to study the fine structure of Aspergillus fumigatus Fres. and A. umbrosus Bainier \& Sartory, two important fungi associated with farmer's lung (Reijula 1991). In the present study, we describe the fine structure of both hyphal fragments and conidia of S. chartarum, a fungus which is able to produce highly toxic mycotoxins and which most evidently is associated with symptoms in individuals exposed in buildings with moisture problems. The pathogenesis of $S$. chartarum-induced disorders has not yet been clarified. However, we have recently shown that toxic spores of $S$. chartarum are able to cause a severe lung injury with necrotic lesions in experimental animals (Nikulin et al. 1996). The knowledge of the fine structure of this important fungus helps researchers to localize the fragments of fungi in lungs of experimental animals by using thin sections of lung tissue and electron microscopy. We also wanted to determine if there is any morphological differences between toxic and non-toxic strains of $S$. chartarum.

\section{Methods}

Organisms and growth conditions

The fine structure of two Stachybotrys chartarum strains (S. 29 and S. 72) was investigated: strain S. 72 is toxigenic while strain S. 29 is non-toxigenic. Strain S. 72 (NRRL 6084) was isolated from hay and the strain 29 from rye in the 1970's in Finland. Both strains were identified as S. chartarum at the Centraalbureau voor Schimmelcultures, Baarn, The Netherlands. For toxicity analysis the strains were cultured on moistened rice (65\% wet-weight basis) for two weeks at $20-23^{\circ} \mathrm{C}$ and two weeks at $6-8^{\circ} \mathrm{C}$. Toxins were extracted with methanol and the toxicity of crude extracts were determined by the cytotoxicity test as previously described (Pasanen et al. 1994).

\section{Electron microscopy}

For electron microscopy strains were cultured for eight days (young culture) and four weeks (old culture) on $2 \%$ malt extract agar (Difco, Michigan, USA) at $20-23^{\circ} \mathrm{C}$. Small pieces of young and old cultures were fixed with
$500 \mu \mathrm{l} 2.5 \%$ glutaraldehyde (Electron Microscopy Sciences, Forth Washington, USA) for several days.

The specimens were postfixed in osmiumtetroxide, dehydrated in alcohol, and embedded in Epon-Araldite mixture. Semithin sections were made on an LKB U1tratome $\mathrm{V}$ and stained with toluidine blue. Ultrathin sections were also made on an LKB Ultratome V and stained with uranyl acetate and lead citrate. The specimens were examined on a JEOL Temscan $100 \mathrm{CX}$ electron microscope at $60 \mathrm{kV}$.

\section{Results}

In young cultures (eight days old) of $S$. chartarum there were only few conidia. Therefore, conidial ultrastructure was studied from older cultures. Light microscopic findings of S. chartarum-conidia and hyphae are shown in Figures 1 and 2.

\section{Stachybotrys chartarum S. 72 (toxic strain)}

The width of the parent hyphae (Figs. 1 and 3) varied from 1.7-3.8 $\mu \mathrm{m}$. The cell wall of the hypha, $410-700 \mathrm{~nm}$ in thickness, consisted of three layers: an electron lucent inner layer, a more dense middle layer, and an electron dense outer layer. The outer layer was uneven and often covered with loose, homogenous electron dense material. Mitochondria, smooth endoplasmic reticulum, vesicles and glycogen granules were present in the cytoplasm.

The ellipsoidal conidia (Figs. 2 and 4) measured 3.1 to $5.2 \mu \mathrm{m}$ in diameter. Conidial cell wall varied from $310-720 \mathrm{~nm}$. Three wall layers could be detected in the conidia. The electron dense outer layer was uneven and formed an echinulate surface configuration to the conidia. Electron dense material was loosely connected, and often detached, to the surface of the conidia. The more dense middle layer was thinner than the outer layer and merged with the inner layer of the conidial wall without a clear demarcation. The electron lucent, homogenous inner layer of the conidial wall appeared in a close connection with the plasma membrane. There was a single nucleus, and the cytoplasm contained mitochondria, glycogen granules and free ribosomes.

\section{Stachybotrys chartarum S. 29 (non-toxic strain)}

The width of the hyphae (Fig. 5) varied from 1.9 to $4.2 \mu \mathrm{m}$ in diameter. The cell wall of the hypha, 300 to $610 \mathrm{~nm}$ in thickness, consisted of a 


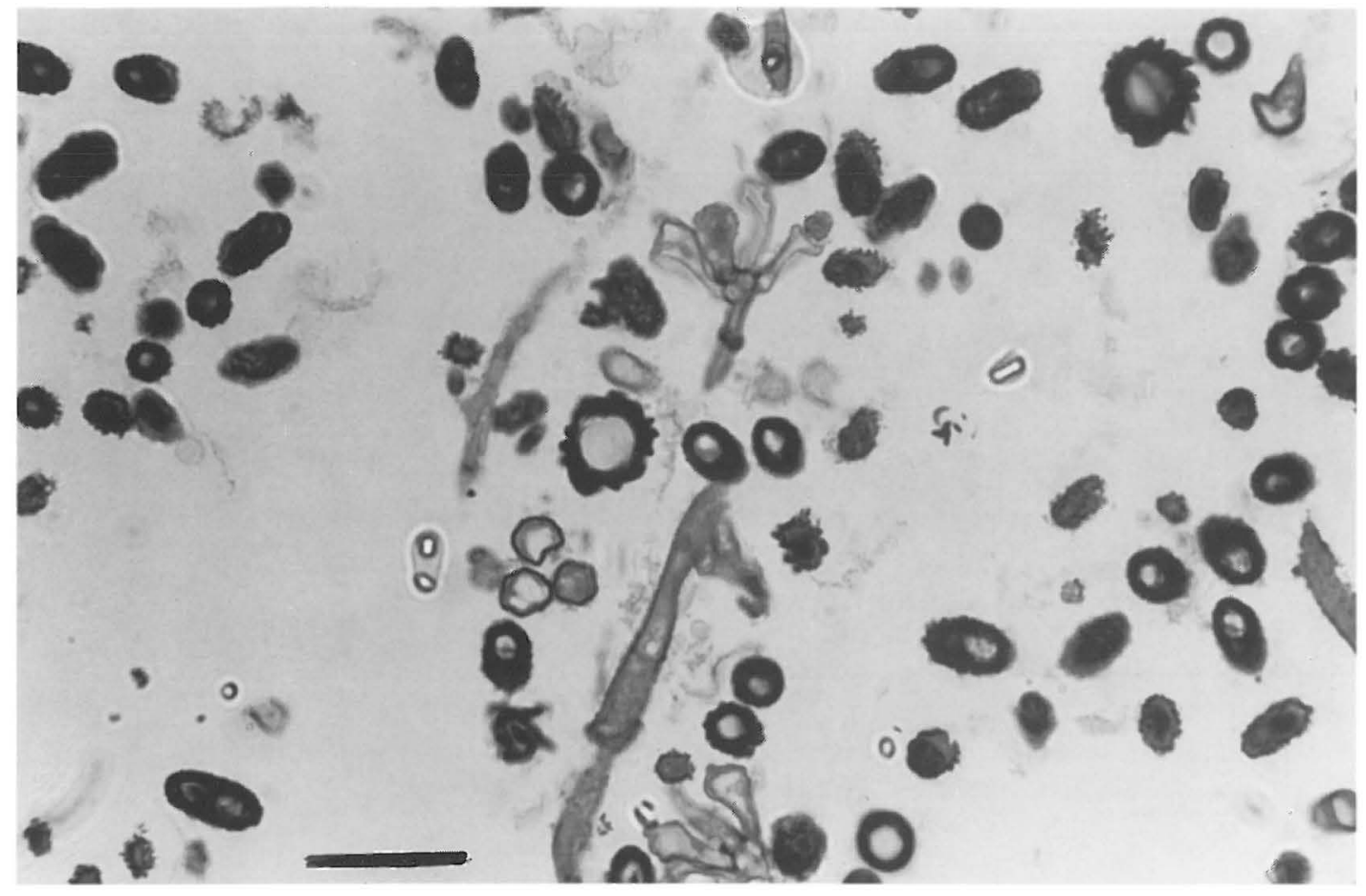

Fig. 1. Stachybotrys chartarum S.72: Semithin section of the microbe. Spores, conidiophore and hyphae (bar $6 \mu \mathrm{m})$.

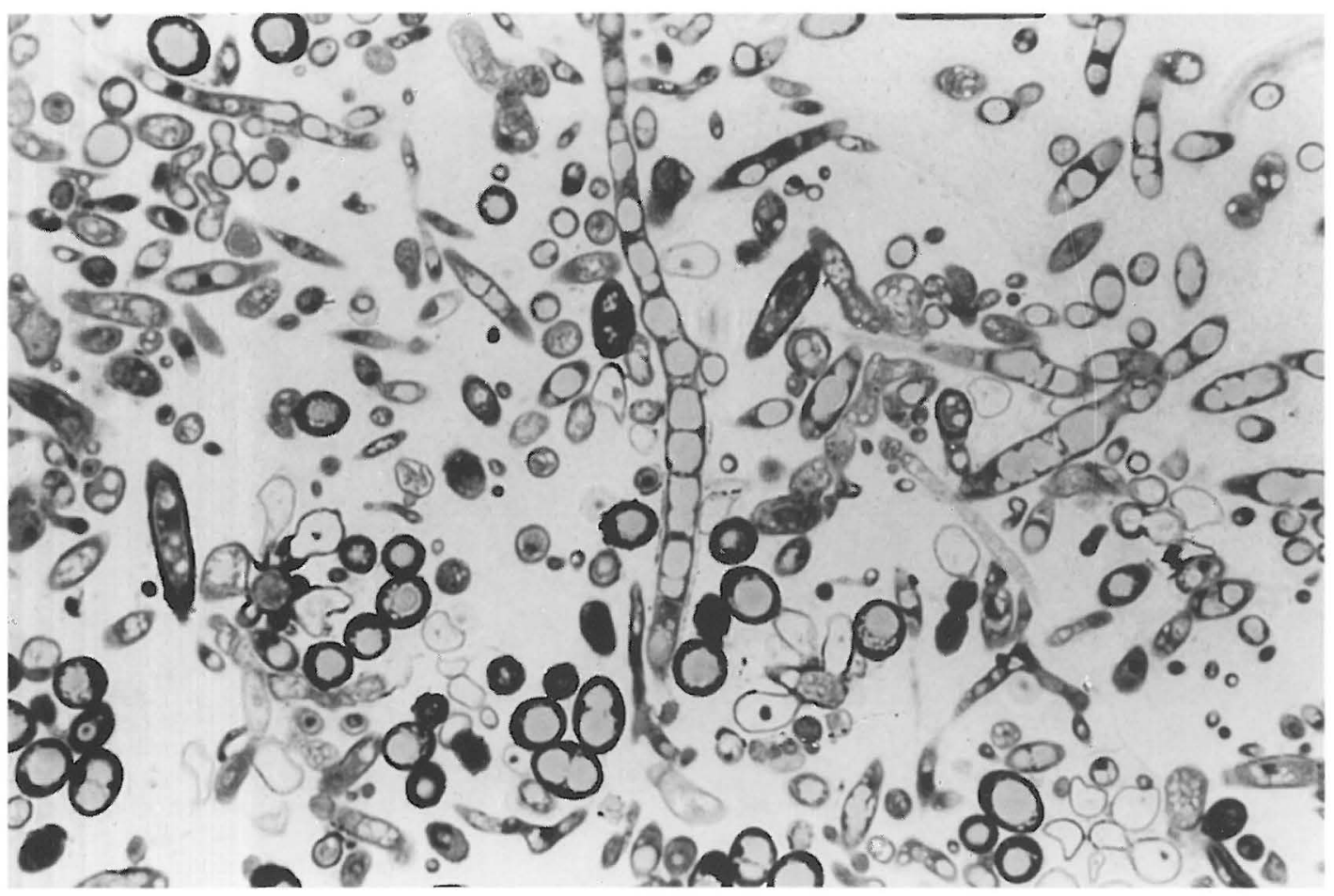

Fig. 2. Stachybotrys chartarum S.29: Semithin section of the fungus. Spores and hyphae (bar $6 \mu \mathrm{m}$ ). 


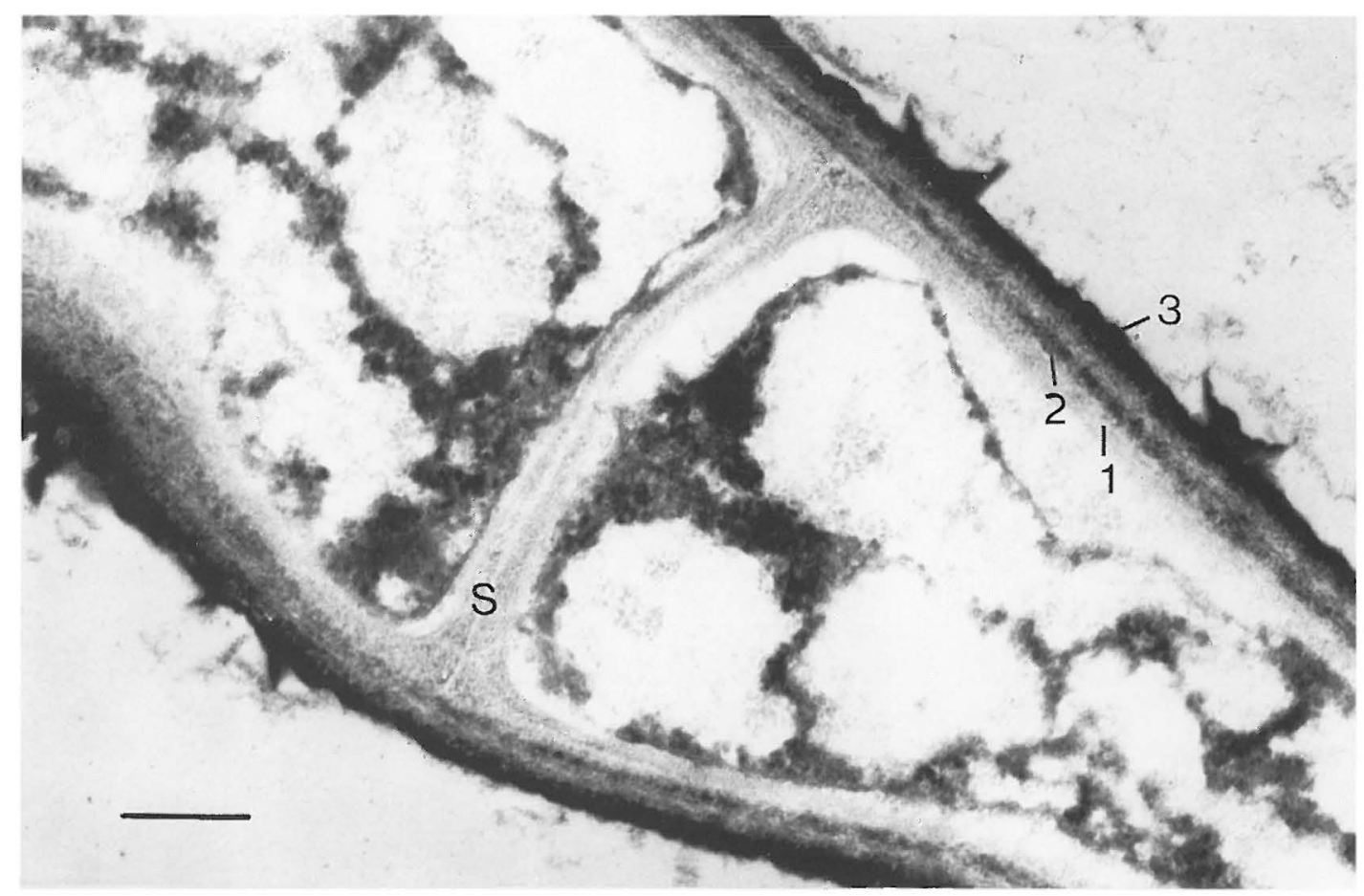

Fig. 3. Stachybotrys chartarum S.72: Thin section of a hyphal fragment. Three layers (\#1-3) are visible in the cell wall. Outer surface is uneven and covered with electron dense material. Septum (S) divides the hypha. Endoplasmic reticulum and ribosomes are present in cytoplasm (bar $0.5 \mu \mathrm{m})$.

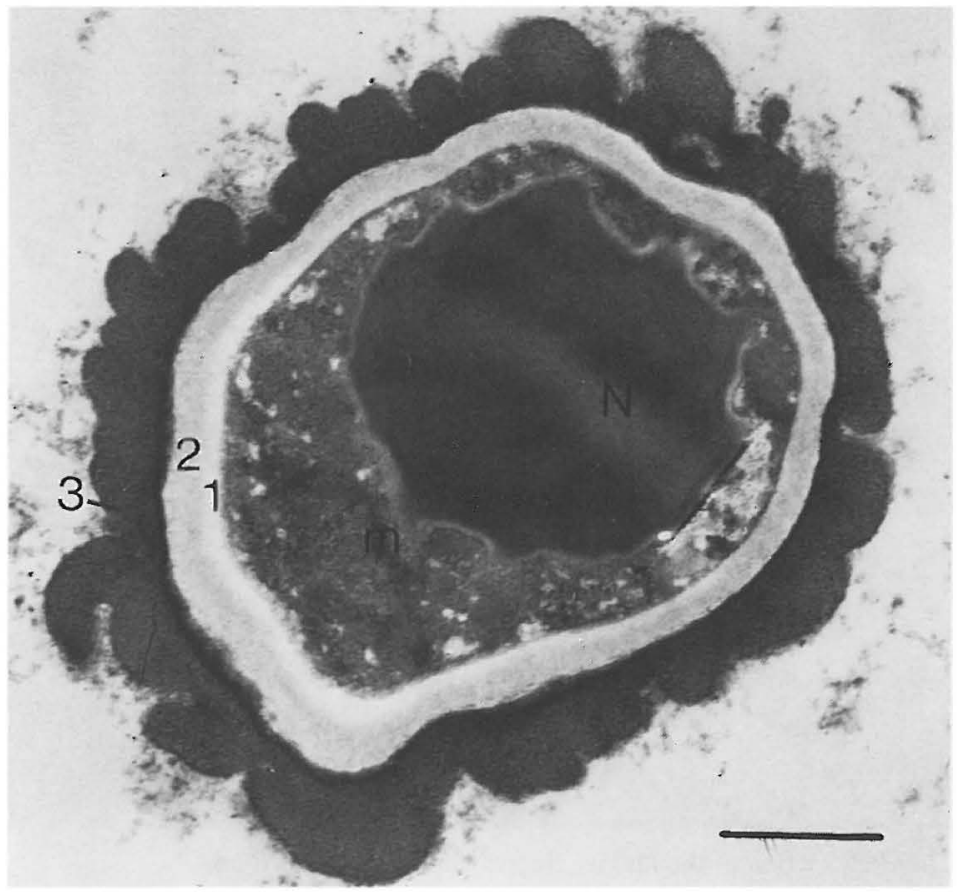

Fig. 4. Stachybotrys chartarum S 72: A mature conidium with a prominent, electron dense outer surface (\#3) and the other two cell wall layers (\#1-2). A single nucleus (N), mitochondria (m) and glycogen granules are visible in the cytoplasm (bar $1 \mu \mathrm{m}$ ). 


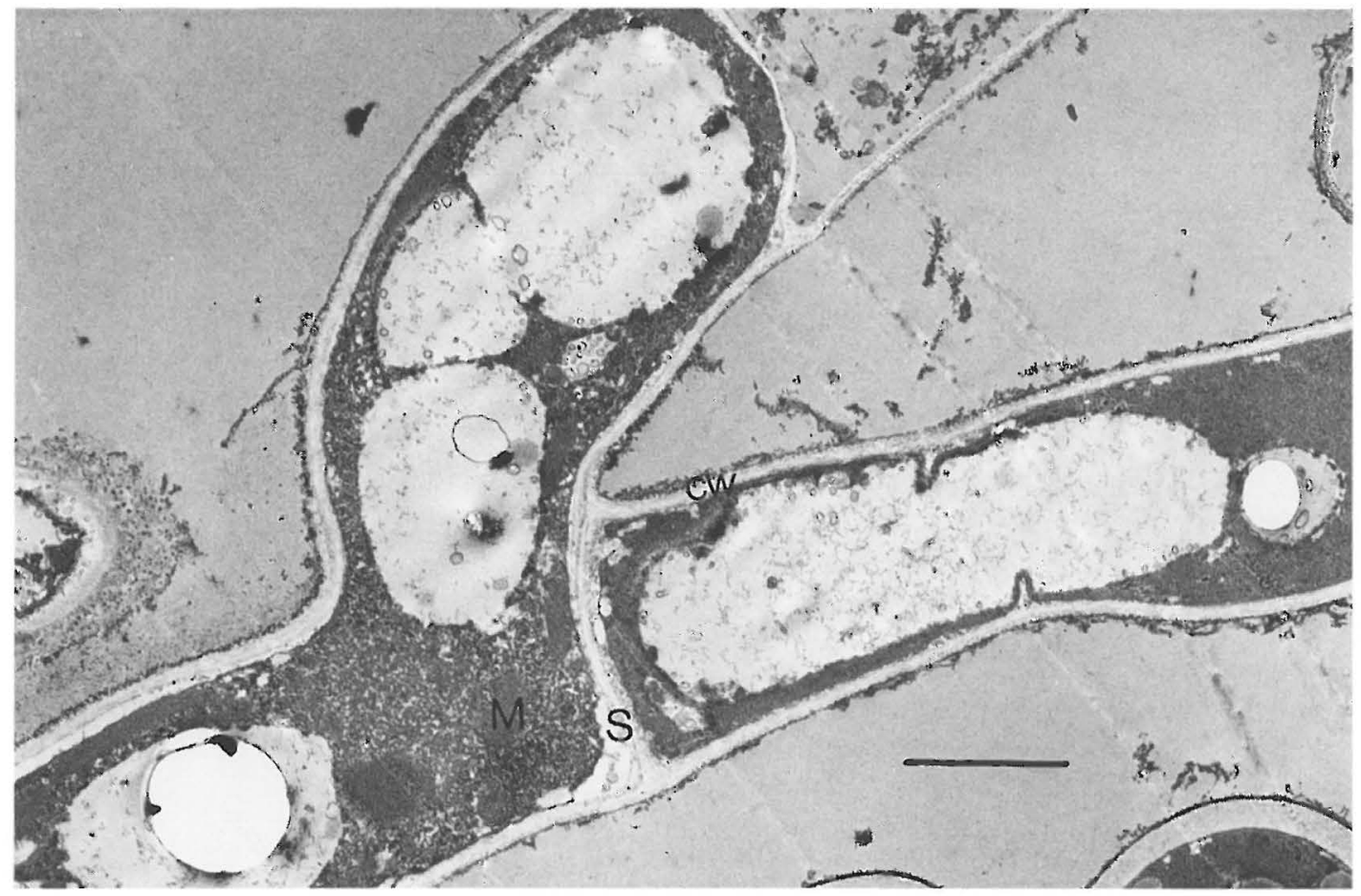

Fig. 5. Stachybotrys chartarum S 29. Hyphal fragment of the fungus. Electron lucent cell wall (CW) consists of three wall layers. The electron dense outer layer is often detached from the inner layers. Septum (S) is visible between the cells. Mitochondria (M) can be seen in cytoplasm (bar $2 \mu \mathrm{m})$.

Fig. 6. Stachybotrys chartarum S 29. A mature conidium with an electron dense outer surface (\#3), and two less dense layers (\#1-2). A single nucleus (N) and mitochondria (M) are visible in cytoplasm (bar $1 \mu \mathrm{m})$.

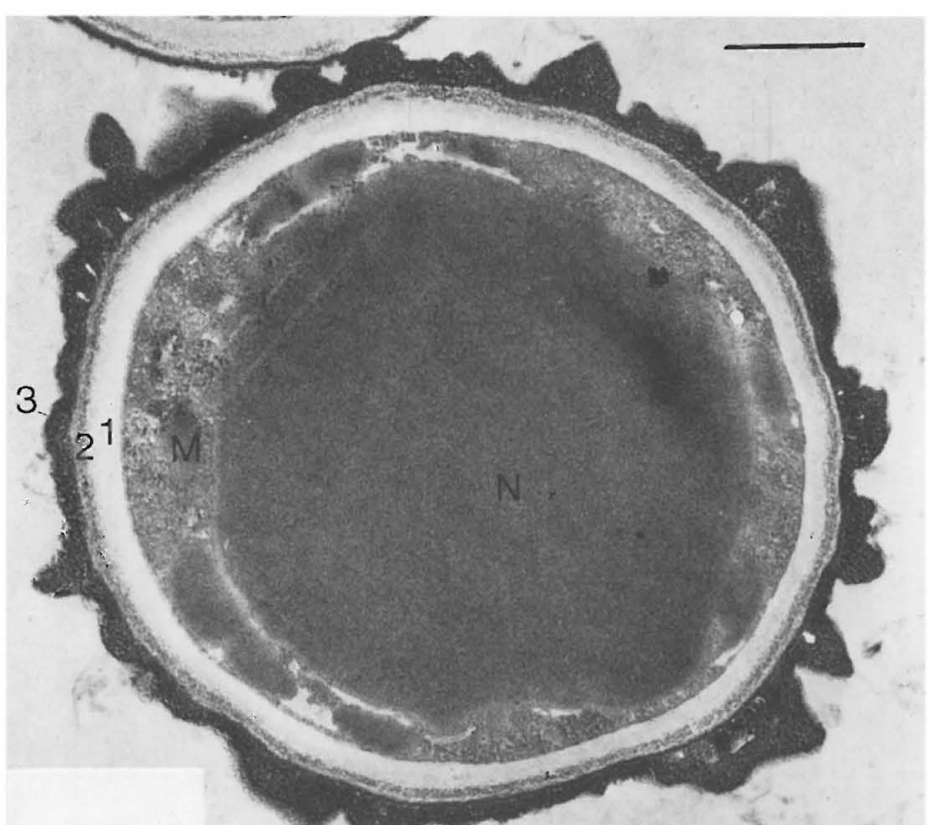




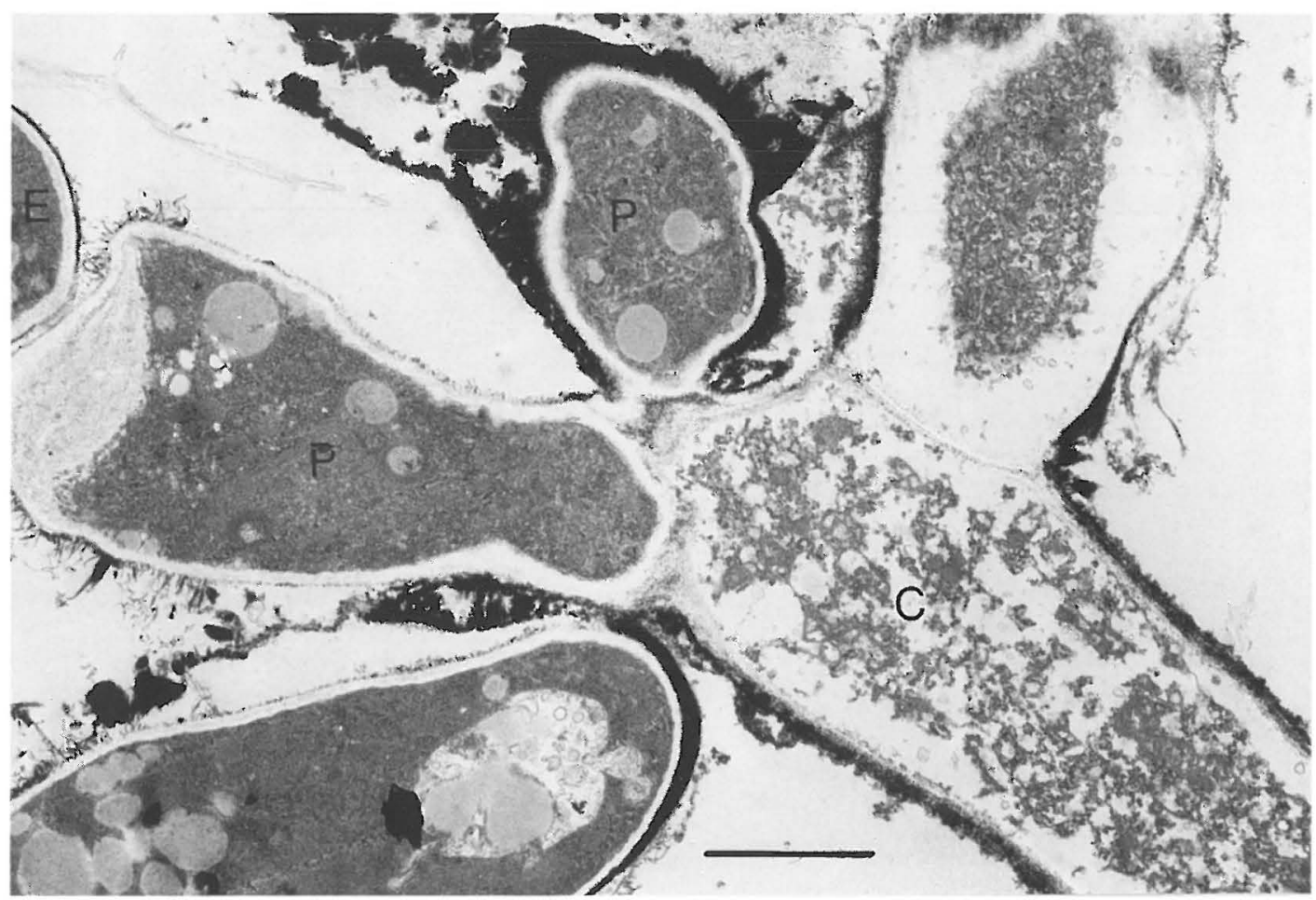

Fig. 7. Stachybotrys chartarum S 29. Conidiophore (C) and four phialides (P) of the fungus. Phialides contain mitochondria, glycogen granules and vesicles. One phialide is loosely connected to an endoconidium (E) (bar $2 \mu \mathrm{m})$.

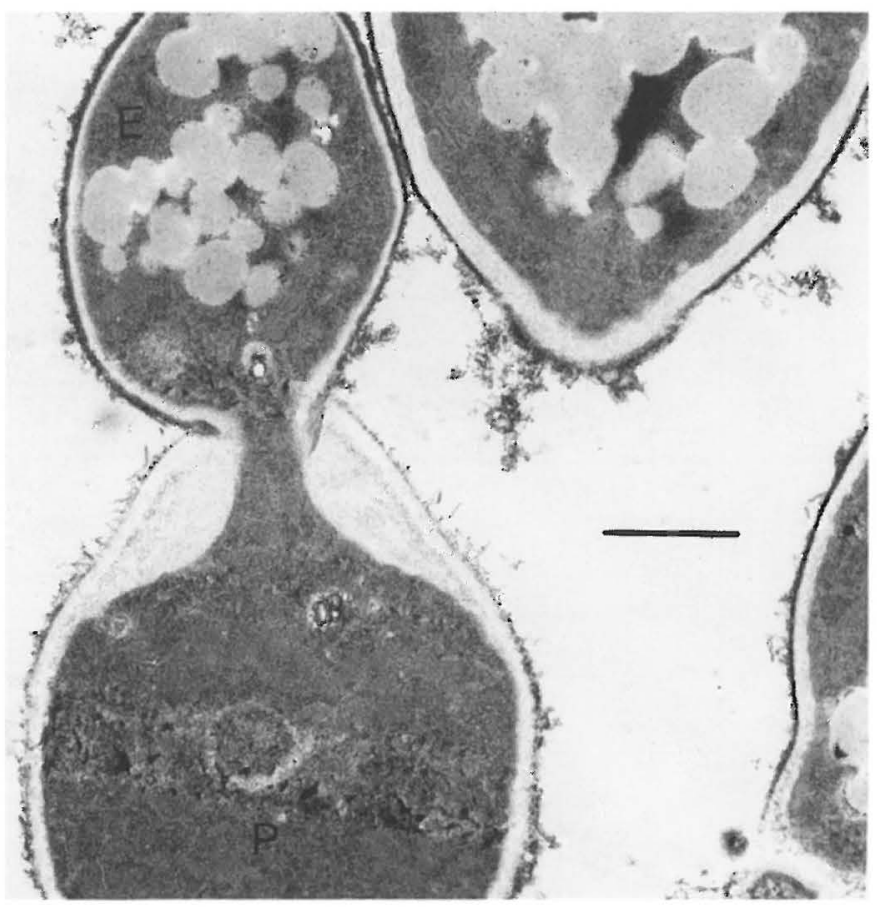

Fig. 8. Stachybotrys chartarum S 29. More detailed illustration of the emergence of an endoconidium (E). Note the narrow channel between the phialide $(\mathrm{P})$ and the endoconidium (E) in which the cytoplasmic material is transferred from the phialide. Note glycogen granules in conidium (bar $1 \mu \mathrm{m}$ ). 
lucent and homogenous material which was closely connected with the plasma membrane. The electron dense outer layer was often detached from the inner layer of the hyphae. Mitochondria, smooth endoplasmic reticulum, ribosomes, vesicles and glycogen granules could be detected in the cytoplasm. The outer surface of the S. 29 hyphae was smoother than in S. 72.

The conidia (Fig. 6) measured 4.9 to $6.4 \mu \mathrm{m}$ in diameter. The conidial wall varied from 300 to $750 \mathrm{~nm}$ in thickness. Three wall layers could be detected in the conidia. The electron dense outer layer was uneven but closely connected to a more dense middle layer of the cell wall. The junction between the electron lucent homogeneous inner layer of the conidial wall and the plasma membrane lacked a clear demarcation. A nucleus, mitochondria, glycogen granules and ribosomes were visible in the cytoplasm.

The conidiophores of S. 72 and S. 29 (Fig. 7) measured from 3.1 to $4.2 \mu \mathrm{m}$ in diameter were unbranched, and bore 3 to 5 phialides, 4.2 to 8.5 $\mu \mathrm{m}$ in length. Cytoplasm from the phialides was transferred in to immature phialoconidium through a narrow channel (Fig. 8).

\section{Discussion}

To our knowledge this is the first description of the fine structure of both hyphal and conidial morphology of $S$. chartarum which recently has been associated with symptoms documented in persons occupying buildings with moisture problems. There is an urgent need to investigate the pathogenesis of $S$. chartarum-induced respiratory and dermal disorders both in man and animals. Animal experiments and lung histology can be used in studying the inflammatory responses in lungs after the exposure to $S$. chartarum. In order to understand the mechanisms of lung injury in exposed animals one has to know the ultrastructure of the causative agent. Therefore, the fine structure of $S$. chartarum was analyzed in the present study. TEM will also be used in studies of lung ultrastructure in experimental animals.

Campbell (1972) used electron microscopy to illustrate the conidium ontogeny of $S$. atra Corda, now considered to be the same species as $S$. chartarum (Jong \& Davis 1976). Campbell (1972) did not report of the morphology of $S$. atra hyphae. According to Campbell (1972), co- nidia were produced through the tips of the clusters of phialides into the slime drop borne on the top of the conidiophore. The cell wall of conidia was two layered and the outer layer was electron dense and had a rough surface. The usual cell organelles (nucleus, mitochondrion, endoplasmic reticulum, ribosomes) were present in the conidia. In the present study, the formation of conidia occurred as published by Campbell (1972). The conidium was ellipsoidal containing three layers and outer layer was electron dense, uneven and echinulate in both strains of $S$. chartarum. Cytoplasm was transferred from the phialides to immature phialoconidium through a narrow channel during conidium maturation.

According to previous literature (Jong \& Davis 1976, Campbell 1972), young hyphae of $S$. chartarum are hyaline, but become olive gray-brown with age and measure $2-4 \mu \mathrm{m}$ in thickness. Conidiophores are simple or branched, about $100 \mu \mathrm{m}$ tall and 3-6 $\mu \mathrm{m}$ wide with a few septa. The upper, darker part of the conidiophore bears a group of phialides (4-10). These are hyaline or dark-colored and ellipsoidal, 9-14 $\times 4-6 \mu \mathrm{m}$. Conidia of $S$. chartarum are ellipsoidal, 5-7 $\times 8-12 \mu \mathrm{m}$, hyaline at first and later dark-colored, smooth-walled or occasionally showing short spiny structures (Jong \& Davis 1976 , Gravensen et al. 1994, Samson \& van Reenen-Hoekstra 1988).

In the present study, the cell wall of the hypha in both strains of $S$. chartarum contained three layers and mitochondria, endoplasmic reticulum, ribosomes and also vesicles and glycogen granules were detected in cytoplasm. The conidiophores were unbranched.

Furthermore, we aimed to compare the possible differences in the fine structure of two strains of $S$. chartarum, the first being toxigenic and the other non-toxic. The number of toxic strains isolated from different materials is variable and two-thirds of the strains in a Finnish material from 1970's were toxic (Korpinen \& Uoti 1974). It is not known if certain morphological details of $S$. chartarum are correlated with its toxin-producing ability. It has been suggested that toxin production, spore development, and pigment production occur simultaneously (Hintikka 1977). In the present study, significant morphological differences were not detected between the toxic and non-toxic strains of $S$. chartarum. However, the outer surface of the hypha of the 
non-toxic strain was smoother than that in the toxic strain and the echinulate surface of conidium of the non-toxic strain was thinner than that in the toxic strain.

Acknowledgements. The present work was supported by the grant from the Research Council for the Environmental Sciences of the Academy of Finland (30978).

\section{References}

Bisset, T.J. 1987: Fungi associated with urea-formaldehyde insulation in Canada. - Mycopathologia 99:4756.

Campbell, R. 1972: Ultrastructure of conidium ontogeny in the deuteromycete fungus Stachybotrys atra Corda. - New Phytol. 71:1143-1149.

Croft, W.A., Jarvis, B.B. \& Yatawara, C.S. 1986: Airborne outbreak of trichothecene toxicosis. - Atm. Environ. 20:549-552.

Gravensen, S., Frisvad, J.C., Samson, R.A. (eds). 1994: Microfungi. HighTech PrePress A/S, Copenhagen, Denmark.

Heikkilä, P., Kotimaa, M., Salmi, T. \& Louhelainen, K. 1988: Identification and counting of fungal spores by scanning electron microscopy. - Ann. Occup. Hyg. 32:241-248.

Hintikka, E.-L. 1977: The genus Stachybotrys. In: Wyllie, T.D., Morehouse, L.G. (eds.), Mycotoxic Fungi. Mycotoxins. Mycotoxicoses: 91-98. - New York: Marcel Deccer Inc.

Hintikka, E.-L. 1978: Human stachybotryotoxicosis. In: Wyllie, T.D., Morehouse, L.G., (eds.), Mycotoxic Fungi. Mycotoxins. Mycotoxicoses: 87-89. - New York: Marcel Deccer Inc.

Hunter, C.A., Grant, C., Flannigan, B. \& Bravery, A.F. 1988: Mould in buildings: the air spora of domestic dwellings. -- Int. Biodeter. 24:81-101.

Jarvis, B.B. 1991: Macrocyclic trichothecenes. In: Sharma, R.P., Salunkhe, D.K. (eds.), Mycotoxins and Phytoalexins: 361-421. - Boca Raton, Florida: CRC Press.
Jarvis, B.B., Salemme, J. \& Morais, A. 1995: Stachybotrys toxins. - Nat. Tox. 3:10-16.

Johanning, E., Morey, P.R. \& Goldberg, M. 1993: Remedial techniques and medical surveillance program for the handling of toxigenic Stachybotrys atra. In: Kalliokoski, P., Jantunen, M., Seppänen, O., (eds.). Proceedings of the 6th International Conference on Indoor Air Quality and Climate: 311-316. - Helsinki: Gummerus Oy, Finland.

Jong, S.C. \& Davis, E.E. 1976: Contribution to the knowledge of Stachybotrys and Memnoniella in culture. - Mycotaxon 3:409-485.

Korpinen, E.-L. \& Uoti, J. 1974: Studies on Stachybotrys alterans II. Occurrence, morphology and toxigenicity. - Acta Path. Microbiol. Immunol. Scand. (Section B) 82:1-6.

Marasas, W.F.O. \& Nelson, P.E. 1987: Stachybotryotoxicosis. In: Marasas, W.F.O., Nelson, P.E. (eds.), Mycotoxicology: 38-40. - The Pennsylvania State University Press, University Park, USA.

Miller, J.D., Laflamme, A.M., Sobol, Y., Lafontaine, P. \& Greenhalgh, R. 1988: Fungi and fungal products in some Canadian houses. - Int. Biodeter. 24:103-120.

Nikulin, M., Pasanen, A.-L., Berg, S. \& Hintikka, E.-L. 1994: Stachybotrys atra growth and toxin production in some building materials and fodder under different relative humidities. - Appl. Environ. Microbiol. 60:3421-3424.

Nikulin, M., Reijula, K., Jarvis, B.B. \& Hintikka, E.-L. 1996: Experimental lung mycotoxicosis in mice induced by Stachybotrys atra. - Int. J. Exp. Path. 77:213-218.

Pasanen, A.-L., Nikulin, M., Berg, S. \& Hintikka, E.-L. 1994: Stachybotrys atra Corda may produce mycotoxins in respirator filters in humid environments. Am. Ind. Hyg. Assoc. J. 55:62-65.

Reijula, K.E. 1991: Two common fungi associated with farmer's lung: fine structure of Aspergillus fumigatus and Aspergillus umbrosus. - Mycopathologia 113:143-149.

Samson, R.A., Stalpers, J.A. \& Verkerke, W. 1979: A simplified technique to prepare fungal specimens for scanning electron microscopy. - Cytobios. 24:7-11.

Samson, R.A. \& Van Reenen-Hoekstra, E.S. 1988: Introduction to food-borne fungi. $-299 \mathrm{pp}$. Centraalbureau voor Schimmelcultures, Baarn, The Netherlands.

Sorenson, W.G., Frazer, D.G., Jarvis, B.B., Simpson, J. \& Robinson, V.A. 1987: Trichothecene mycotoxins in aerosolized conidia of Stachybotrys atra. - Appl. Environ. Microbiol. 53:1370-1375.

Received on 24 April 1997 